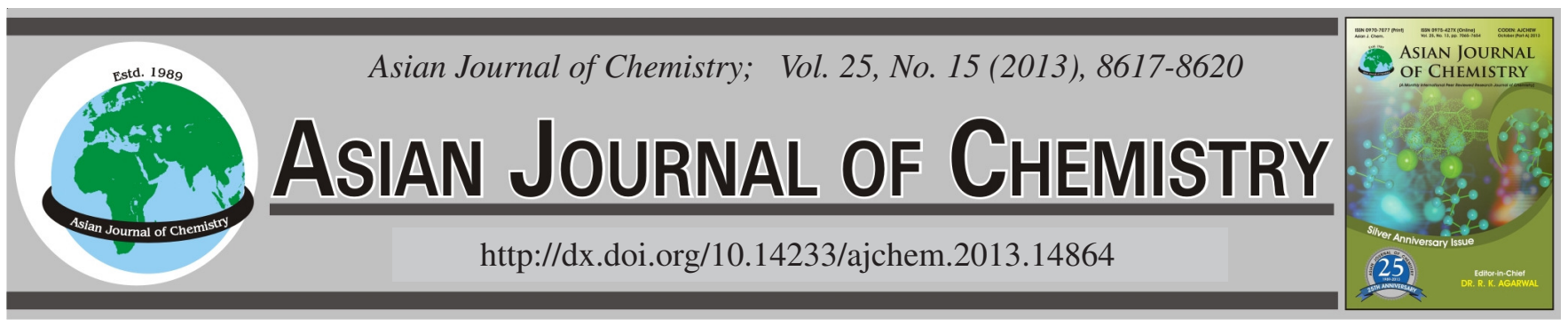

\title{
Selectivity of Gold Catalysts for Selective Hydrogenation of Cinnamaldehyde
}

\author{
YingXIN LiU ${ }^{1, *}$, Yiming LuO ${ }^{1}$ and ZuOJUN WeI ${ }^{2}$
}

${ }^{1}$ College of Pharmaceutical Science, Zhejiang University of Technology, Hangzhou 310032, Zhejiang, P.R. China

${ }^{2}$ Institute of Pharmaceutical Engineering, Department of Chemical and Biochemical Engineering, Zhejiang University, Hangzhou 310027 , Zhejiang, P.R. China

*Corresponding author: Fax: +86 571 88320064; Tel: +86 571 88320064; E-mail: yxliu@ zjut.edu.cn

Gold nanoparticles (AuNPs), $\mathrm{SiO}_{2}$ and $\mathrm{TiO}_{2}$ supported AuNPs prepared by colloid deposition method and $\mathrm{Au} / \mathrm{TiO}_{2}$ prepared by depositionprecipitation method $\left(\mathrm{Au} / \mathrm{TiO}_{2}-\mathrm{DP}\right)$ were used for the liquid-phase selective hydrogenation of cinnamaldehyde. The catalysts were characterized by HRTEM, $\mathrm{H}_{2}$-TPR and XPS. Results showed that AuNPs, AuNPs/SiO ${ }_{2}$ and $\mathrm{AuNPs} / \mathrm{TiO}{ }_{2}$ in dried form selectively hydrogenated the $\mathrm{C}=\mathrm{C}$ bond, whereas $\mathrm{AuNPs} / \mathrm{TiO} \mathrm{O}_{2}$ treated in $\mathrm{H}_{2}$ and $\mathrm{Au} / \mathrm{TiO}_{2}-\mathrm{DP}$ preferentially hydrogenated the conjugated $\mathrm{C}=\mathrm{O}$ bond. From our data, high selectivity toward cinnamyl acohol could be mainly attributed to an electron transfer from the reduced support to gold, which creates more electron-enriched gold particles, favouring $\mathrm{C}=\mathrm{O}$ hydrogenation.

Key Words: Gold catalyst, Cinnamaldehyde, Selective hydrogenation, Cinnamyl acohol.

\section{INTRODUCTION}

The selective hydrogenation of $\alpha, \beta$-unsaturated aldehydes to the corresponding unsaturated alcohols, an important procedure in the synthesis of fine chemicals and pharmaceuticals, is a difficult task, since thermodynamics favours $\mathrm{C}=\mathrm{C}$ hydrogenation over the conjugated $\mathrm{C}=\mathrm{O}$ bond $^{1-3}$. Most of the classical heterogeneous hydrogenation catalysts $(\mathrm{Pt}, \mathrm{Pd}, \mathrm{Ru}$, $\mathrm{Ni}$, etc.) show no or low selectivity toward $\mathrm{C}=\mathrm{O}$ hydrogenation $^{3}$. In recent years, it has been found that supported gold catalysts show remarkable selectivity toward unsaturated alcohols in the hydrogenation of $\alpha, \beta$-unsaturated compounds ${ }^{4-27}$. Many researchers have investigated the factors affecting on the selectivity of gold catalysts to unsaturated alcohols and given different opinions.

Bailie et al. ${ }^{4}$ proposed that active and selective sites for but-2-enal hydrogenation on $\mathrm{Au} / \mathrm{ZnO}$ catalysts are associated with the presence of large gold particles. Claus et al. ${ }^{5,6}$ reported that the selectivity of $\mathrm{Au} / \mathrm{TiO}_{2}$ and $\mathrm{Au} / \mathrm{ZrO}_{2}$ to unsaturated alcohols is favoured by face gold atoms in the larger gold particles. Claus et al. ${ }^{7}$ identified that the edges of single crystalline gold particles are active sites for $\mathrm{C}=\mathrm{O}$ hydrogenation through the decoration of gold particle faces by a second metal indium. This conclusion is in contradiction to the earlier predictions. Lenz et $a l .{ }^{8}$ reported that the selectivity of iron oxides modified alumina supported gold catalysts to unsaturated alcohols is independent of the gold particle size and is related to morphological aspects of gold particles.
Chen et al.$^{9,10}$ found a correlation between the gold states $\left(\mathrm{Au}^{3+} / \mathrm{Au}^{0}\right)$ of $\mathrm{Mg}_{\mathrm{x}} \mathrm{AlO}$ hydrotalcite supported gold catalysts and the catalytic performance. The activity and selectivity to unsaturated alcohols increase with increasing the $\mathrm{Au}^{3+} / \mathrm{Au}^{0}$ ratio of the catalysts.

Some have proposed that the selectivity of gold catalysts towards unsaturated alcohols is strongly influenced by the nature of the support. Reducible oxides $\left(\mathrm{TiO}_{2}, \mathrm{ZrO}_{2}, \mathrm{Fe}_{2} \mathrm{O}_{3}\right.$, etc.) supported gold catalysts selectively hydrogenate the $\mathrm{C}=\mathrm{O}$ bond, while inert oxides (such as $\mathrm{SiO}_{2}$ and $\mathrm{Al}_{2} \mathrm{O}_{3}$ ) supported gold catalysts show no or low selectivity toward $\mathrm{C}=\mathrm{O}$ hydrogenation $^{11-16}$. For example, Bailie and Hutchings ${ }^{11}$ found that the selectivity toward crotyl alcohol in crotonaldehyde hydrogenation is greater than $50 \%$ over $\mathrm{Au} / \mathrm{ZrO}_{2}$ and $\mathrm{Au} / \mathrm{ZnO}$, whereas it is zero over $\mathrm{Au} / \mathrm{SiO}_{2}$. Milone et al. ${ }^{14,15}$ reported that the activity and selectivity of $\mathrm{FeOOH}, \gamma-\mathrm{Fe}_{2} \mathrm{O}_{3}$ and $\alpha-\mathrm{Fe}_{2} \mathrm{O}_{3}$ supported gold to unsaturated alcohols increase with increasing the reducibility of the support in the hydrogenation of benzalacetone and cinnamaldehyde. They argued that active and selective sites are formed by electron-enriched gold particles formed through an electron transfer from the reduced support to gold. Claus et al. ${ }^{12}$ reported that the presence of electron-enriched gold particles favours $\mathrm{C}=\mathrm{O}$ adsorption in the hydrogenation of $\alpha, \beta$-unsaturated aldehydes.

The understanding of the main factors affecting on the selectivity of gold catalysts is necessary for development of tailor-made gold catalysts for the hydrogenation of $\alpha, \beta$ - 
unsaturated compounds. The aim of the present work is to gain a deeper insight into the role of the support in the selectivity of gold catalysts in cinnamaldehyde hydrogenation, an important reaction in the hydrogenation of $\alpha, \beta$-unsaturated aldehydes, by investigating the performances of Au nanoparticles (AuNPs), $\mathrm{SiO}_{2}$ and $\mathrm{TiO}_{2}$ supported AuNPs prepared by colloid deposition method and $\mathrm{Au} / \mathrm{TiO}_{2}$ catalyst prepared by deposition-precipitation method. Combined with the results of characterization and activity/selectivity, the origin of the selectivity of gold catalysts to cinnamyl alcohol was proposed.

\section{EXPERIMENTAL}

Catalyst preparation: Gold nanoparticles were prepared by the reduction of $\mathrm{AuCl}_{4}{ }^{1-}$ ions using $\mathrm{KBH}_{4}\left(\right.$ molar $\mathrm{KBH}_{4} / \mathrm{Au}$ $=3: 1$ ) in water-isopropanol solutions containing a certain amount of PVP (molar PVP/Au $=20: 1$ ) at $30^{\circ} \mathrm{C}$ under vigorous stirring. After $1 \mathrm{~h}$, a brown solution was obtained, indicating the formation of gold colloid ${ }^{28}$.

Supported AuNPs were prepared by colloid deposition method as follows: adding a desirable amount of $\mathrm{SiO}_{2}$ (Qingdao Haiyang Chem, $400 \mathrm{~m}^{2} \mathrm{~g}^{-1}$ ) or $\mathrm{TiO}_{2}$ (prepared as in Ref. ${ }^{23}, 60$ $\mathrm{m}^{2} \mathrm{~g}^{-1}$ ) to the colloidal gold solution under stirring until total adsorption ( 2 wt. \% Au) occurred, indicated by decoloration of the solution. The solids were separated, washed with deionized water and dried in air at $100{ }^{\circ} \mathrm{C}$ for $2 \mathrm{~h}$. The as-prepared catalysts were named as AuNPs/SiO$/ 2 /$ dried and $\mathrm{AuNPs} / \mathrm{TiO}_{2} /$ dried. A part of the two samples were then treated in hydrogen flow at $200{ }^{\circ} \mathrm{C}$ for $3 \mathrm{~h}$ and named as AuNPs/SiO$/$ reduced and AuNPs $/ \mathrm{TiO}_{2} /$ reduced.

$\mathrm{Au} / \mathrm{TiO}_{2}$-DP catalyst was prepared by deposition-precipitation method as in Ref. ${ }^{29}$. The gold content was measured by an Elan DRC-e ICP-MS instrument of PE Inc. USA.

Catalyst characterization: High-resolution transmission electron microscopy (HRTEM) analysis was performed on a Tecnai G2 F30 S-Twin equipment. Hydrogen temperatureprogrammed reduction $\left(\mathrm{H}_{2}-\mathrm{TPR}\right)$ of the catalyst was carried out in a FINESORB-3010 chemical adsorption instrument, heating the sample $(0.1 \mathrm{~g})$ from room temperature to $700{ }^{\circ} \mathrm{C}$ at a rate of $10^{\circ} \mathrm{C} \mathrm{min}^{-1}$ under $20 \mathrm{H}_{2} / \mathrm{Ar}$ (vol \%) at a flow rate of $40 \mathrm{~mL} \mathrm{~min}^{-1}$. The effluent hydrogen concentration was detected with a thermal conductivity detector (TCD). X-Ray photoelectron spectroscopy (XPS) spectra were recorded on a Kratos AXIS Ultra DLD instrument equipped with a monochromatic $\mathrm{AlK}_{\alpha} \mathrm{X}$-ray excitation source $(1486.6 \mathrm{eV})$.

Catalytic activity test: The liquid phase selective hydrogenation of cinnamaldehyde was carried out in a $100 \mathrm{~mL}$ stainless steel autoclave equipped with magnetic stirring at $100^{\circ} \mathrm{C}$ and 2.0 $\mathrm{MPa} \mathrm{H}_{2}$. The following conditions were applied over all the supported gold catalysts: cinnamaldehyde $2.5 \mathrm{~mL}$, isopropanol $50 \mathrm{~mL}$, catalyst $0.5 \mathrm{~g}$. Over AuNPs, the reaction was carried out in $50 \mathrm{~mL}$ isopropanol using $0.5 \mathrm{~mL}$ cinnamaldehyde and $0.125 \mathrm{mmol}$ catalyst (molar cinnamaldehyde $/ \mathrm{Au}=30$ ). The reaction products were analyzed using a gas chromatograph equipped with a HP-5 capillary column and a flame ionization detector.

\section{RESULTS AND DISCUSSION}

The results of cinnamaldehyde hydrogenation over different gold catalysts are listed in Table-1. The catalytic activity is expressed as the initial rate of cinnamaldehyde hydrogenation per gram of gold. It can be seen that the activity of the gold catalysts investigated was affected by the support and the preparation method, following the order: AuNPs $<$ AuNPs/ $\mathrm{SiO}_{2} /$ reduced $<$ AuNPs $/ \mathrm{SiO}_{2} /$ dried $<$ AuNPs $/ \mathrm{TiO}_{2} /$ dried $<\mathrm{Au} /$ $\mathrm{TiO}_{2}$-DP $<$ AuNPs $/ \mathrm{TiO}_{2} /$ reduced.

Table-1 showed that the gold catalysts investigated showed remarkably different selectivity. Unsupported and inert $\mathrm{SiO}_{2}$ supported AuNPs in dried form as well as in reduced form showed high selectivity toward hydrocinnamaldehyde (HCAL), the product of $\mathrm{C}=\mathrm{C}$ hydrogenation in cinnamaldehyde, with lower than $7 \%$ selectivity toward cinnamyl alcohol (COL), the product of $\mathrm{C}=\mathrm{O}$ hydrogenation. This result is in agreement with that reported by Xu et al. ${ }^{30}$ in which $\mathrm{SiO}_{2}$ supported gold nanoparticles prepared by colloid deposition method show high selectivity to $\mathrm{C}=\mathrm{C}$ hydrogenation in cinnamaldehyde. It is worth noting that $\mathrm{TiO}_{2}$ supported AuNPs showed a significant difference in selectivity before and after being treated in $\mathrm{H}_{2}$ at $200{ }^{\circ} \mathrm{C}$ for $3 \mathrm{~h}$. AuNPs/TiO $/$ dried showed higher preference for $\mathrm{C}=\mathrm{C}$ hydrogenation over $\mathrm{C}=\mathrm{O}$, similar to the unsupported and $\mathrm{SiO}_{2}$ supported AuNPs. However, AuNPs/TiO $/$ reduced preferentially hydrogenated the $\mathrm{C}=\mathrm{O}$ bond, similar to $\mathrm{Au} / \mathrm{TiO}_{2}-\mathrm{DP}$. These results suggest that $\mathrm{TiO}_{2}$ by itself is not sufficient to enhance $\mathrm{C}=\mathrm{O}$ hydrogenation with respect to the $\mathrm{C}=\mathrm{C}$ bond in cinnamaldehyde hydrogenation and the catalytic behaviour arises from a synergetic effect between gold and $\mathrm{TiO}_{2}$.

Fig. 1 shows the TEM and STEM images of the catalysts. The average particle sizes of gold are listed in Table-2. Different particle sizes were obtained on the samples. For AuNPs [Fig. 1(a)], gold particles with an average size of $10.6 \mathrm{~nm}$ were observed. After being supported on $\mathrm{SiO}_{2}$, the average size grew to $c a .16 \mathrm{~nm}$ [Fig. 1(b)], significantly lager than the as-prepared

\begin{tabular}{|c|c|c|c|c|c|c|}
\hline \multirow{3}{*}{ Catalyst } & \multicolumn{5}{|c|}{$\begin{array}{c}\text { TABLE-1 } \\
\text { CINNAMALDEHYDE HYDROGENATION OVER DIFFERENT GOLD CATALYSTS }{ }^{a}\end{array}$} & \\
\hline & \multirow{2}{*}{$\begin{array}{c}\mathrm{Au} \\
(\mathrm{wt} \%)\end{array}$} & \multirow{2}{*}{$\begin{array}{l}\text { Activity } \\
\left(\mathrm{mmol} \mathrm{g}_{\mathrm{gold}}{ }^{-1} \min ^{-1}\right)\end{array}$} & \multirow{2}{*}{$\begin{array}{l}\text { Conversion } \\
(\%)\end{array}$} & \multicolumn{3}{|c|}{ Selectivity (\%) } \\
\hline & & & & HCAL & HCOL & $\mathrm{COL}$ \\
\hline $\mathrm{AuNPs}^{\mathrm{b}}$ & 100 & 0.526 & 98.8 & 63.8 & 0.4 & 1.6 \\
\hline AuNPs/SiO $2 /$ dried & 2.0 & 0.960 & 14.5 & 42.2 & 12.4 & 6.4 \\
\hline AuNPs/SiO $/$ /reduced & 2.0 & 0.715 & 10.8 & 53.8 & 0 & 6.2 \\
\hline $\mathrm{AuNPs} / \mathrm{TiO}_{2} /$ dried & 2.0 & 3.455 & 52.2 & 43.3 & 6.9 & 24.9 \\
\hline $\mathrm{AuNPs} / \mathrm{TiO}_{2} /$ reduced & 2.0 & 4.077 & 61.6 & 21.4 & 6.7 & 49.3 \\
\hline $\mathrm{Au} / \mathrm{TiO}_{2}-\mathrm{DP}$ & 1.9 & 3.741 & 53.7 & 23.0 & 13.3 & 48.7 \\
\hline
\end{tabular}


AuNPs in solution, indicating an agglomeration of gold particles during immobilization. Whereas $\mathrm{TiO}_{2}$ supported AuNPs catalyst [Fig. 1(c)] showed smaller gold particles than unsupported AuNPs. The smallest value of gold particles was found for $\mathrm{Au} / \mathrm{TiO}_{2}$-DP [Fig. 1(d)], with an average particle size of $3.9 \mathrm{~nm}$. Combined with the results of cinnamaldehyde hydrogenation (Table-1), it can be seen that small gold particle size favours the activity of the gold catalysts for cinnamaldehyde hydrogenation, whereas the selectivity of the gold catalysts toward cinnamyl alcohol is not mainly dependent on the gold particle size.

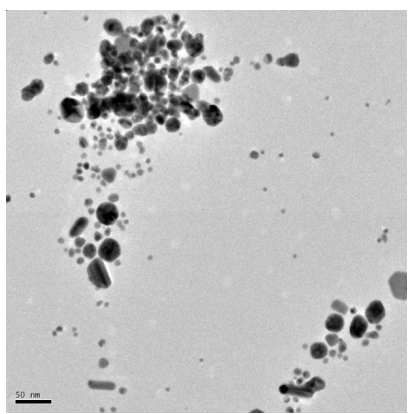

(a)

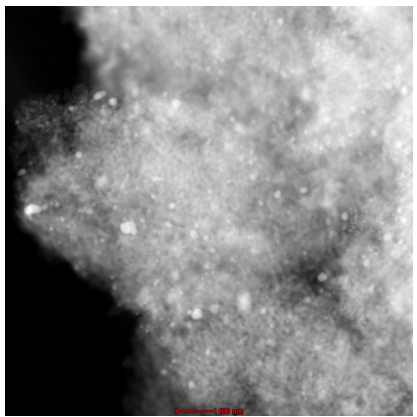

(c)



(b)

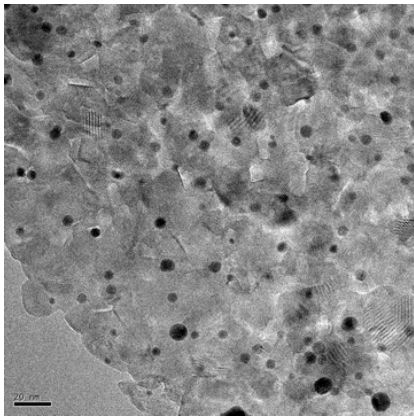

(d)
Fig. 1. TEM and STEM images of gold catalysts: (a) AuNPs; (b) AuNPs/ $\mathrm{SiO}_{2} /$ dried; (c) AuNPs/TiO $/$ dried; (d) $\mathrm{Au} / \mathrm{TiO}_{2}$-DP

TABLE-2

TEM AND XPS RESULTS OF THE GOLD CATALYSTS

\begin{tabular}{lccc}
\hline \multicolumn{1}{c}{ Catalyst } & $\begin{array}{c}\mathrm{d}(\mathrm{nm}) \\
\mathrm{TEM}\end{array}$ & $\begin{array}{c}\mathrm{BE}(\mathrm{eV}) \mathrm{Au} \\
4 \mathrm{f}_{7 / 2}\end{array}$ & $\begin{array}{c}\mathrm{BE}(\mathrm{eV}) \mathrm{Au} \\
4 \mathrm{f}_{5 / 2}\end{array}$ \\
\hline $\mathrm{AuNPs}$ & 10.6 & $83.8(69 \%)$ & $87.4(69 \%)$ \\
& & $85.1(31 \%)$ & $88.6(31 \%)$ \\
$\mathrm{AuNPs} / \mathrm{SiO}_{2} /$ dried & 16.1 & - & - \\
$\mathrm{AuNPs} / \mathrm{TiO}_{2} /$ dried & 8.0 & $83.2(100 \%)$ & $86.8(100 \%)$ \\
$\mathrm{AuNPs} / \mathrm{TiO}_{2} /$ reduced & - & $83.0(100 \%)$ & $86.6(100 \%)$ \\
$\mathrm{Au} / \mathrm{TiO}_{2}-\mathrm{DP}$ & 3.9 & $82.8(100 \%)$ & $86.2(100 \%)$ \\
\hline
\end{tabular}

Fig. 2 shows the TPR profile of $\mathrm{Au} / \mathrm{TiO}_{2}-\mathrm{DP}$ catalyst before reduced in $\mathrm{H}_{2}$. The profile showed two overlapping reduction peaks at higher temperature $\left(500-600{ }^{\circ} \mathrm{C}\right)$, which was assigned to the partial reduction of $\mathrm{TiO}_{2}$ to $\mathrm{TiO}_{2-\mathrm{x}}{ }^{31}$. Generally, $\mathrm{TiO}_{2}$ is difficult to be reduced. It has been reported that the reduction temperature of $\mathrm{TiO}_{2}$ in $\mathrm{H}_{2}$ is at $1300{ }^{\circ} \mathrm{C}^{32}$. Our result indicates that the presence of gold enhances the reducibility of $\mathrm{Ti}^{4+}$ species, which is in accordance with the literature ${ }^{31}$.

Fig. 3 shows the XPS spectra of Au 4f in AuNPs, AuNPs/ $\mathrm{TiO}_{2} /$ dried, AuNPs $/ \mathrm{TiO}_{2} /$ reduced and $\mathrm{Au} / \mathrm{TiO}_{2}$-DP. The corresponding XPS data are summarized in Table-2. XPS data for AuNPs revealed the presence of two different gold species,

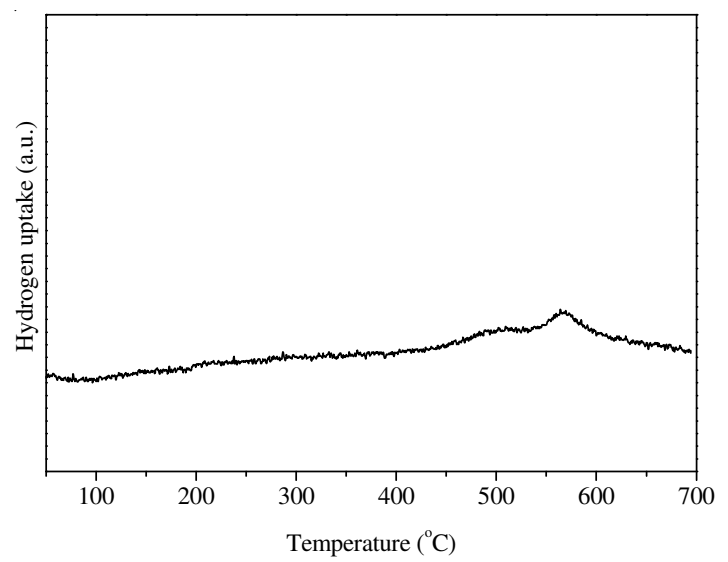

Fig. 2. TPR profile of $\mathrm{Au} / \mathrm{TiO}_{2}-\mathrm{DP}$ catalyst before reduction
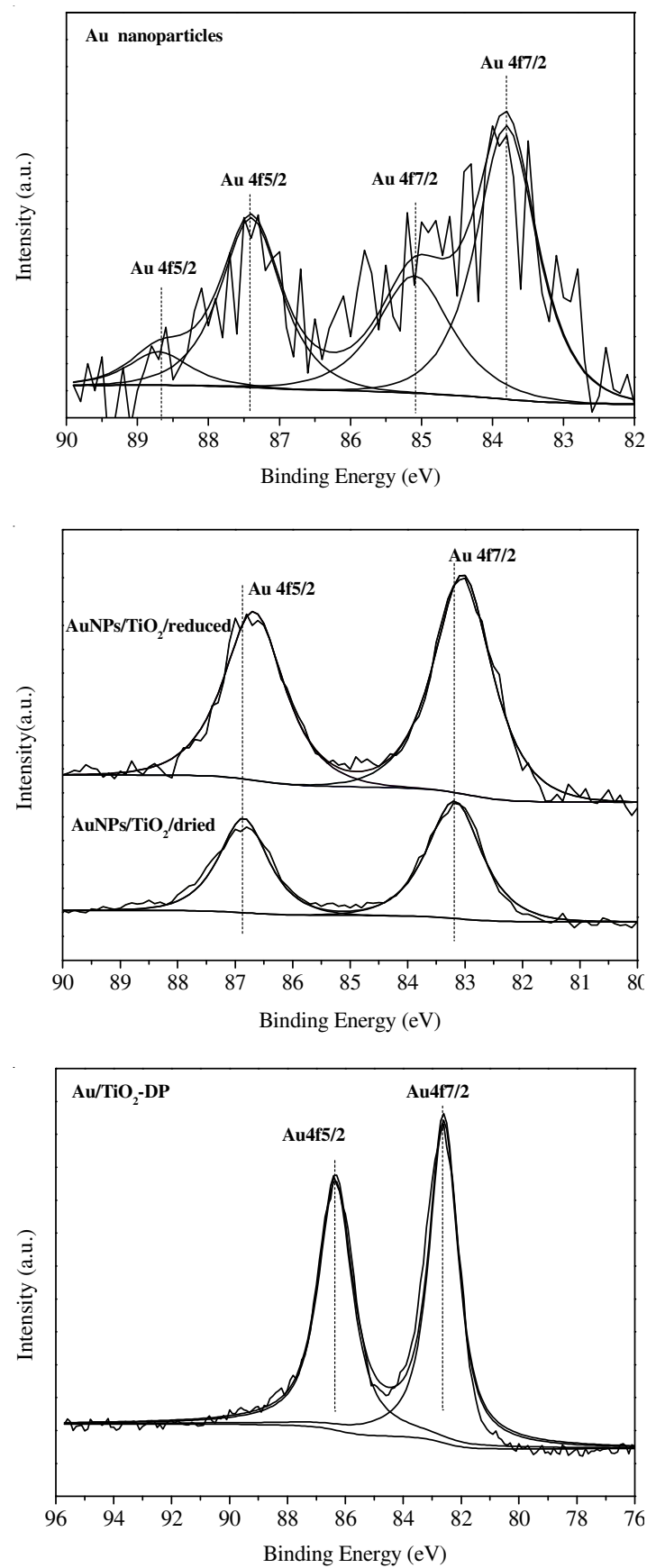

Fig. 3. XPS spectra of Au 4f in AuNPs, AuNPs/TiO $/$ dried, AuNPs $/ \mathrm{TiO}_{2} /$ reduced and $\mathrm{Au} / \mathrm{TiO}_{2}-\mathrm{DP}$ 
$\mathrm{Au}^{0}(83.8$ and $87.4 \mathrm{eV})$ and $\mathrm{Au}^{8+}(85.1 \text { and } 88.6 \mathrm{eV})^{33}$. Whereas for $\mathrm{AuNPs} / \mathrm{TiO}_{2} /$ dried, AuNPs $/ \mathrm{TiO}_{2} /$ reduced and $\mathrm{Au} / \mathrm{TiO}_{2}-\mathrm{DP}$, only the $\mathrm{Au} 4 \mathrm{f}$ peaks assigned to metallic Au were detected. Compared with the Au $4 \mathrm{f}$ binding energies (BEs) for AuNPs, the three $\mathrm{TiO}_{2}$ supported gold catalysts showed lower BEs corresponding to $\mathrm{Au}^{0}$. It should be noted that the treatment of AuNPs/TiO $/$ dried sample in $\mathrm{H}_{2}$ (i.e. AuNPs/TiO $/$ /reduced) led to a significantly negative $\mathrm{BEs}$ shift of the $\mathrm{Au} 4 \mathrm{f}$ peaks. Au/ $\mathrm{TiO}_{2}$-DP showed the most negative shift compared with AuNPs $\left(1.0 \mathrm{eV}\right.$ for $\mathrm{Au} 4 \mathrm{f}_{7 / 2}$ and $1.2 \mathrm{eV}$ for $\left.\mathrm{Au} 4 \mathrm{f}_{5 / 2}\right)$. The negative shift of $\mathrm{Au} 4 \mathrm{f}$ is due to an electron transfer from the reduced support to gold, which lead to the increase in the electron density on gold and can create more electron-enriched gold particles ${ }^{5}$. Combined with the catalytic test results as shown in Table-1, it can be proposed that the high selectivity of $\mathrm{AuNPs} / \mathrm{TiO}_{2} /$ reduced and $\mathrm{Au} / \mathrm{TiO}_{2}$-DP toward cinnamyl alcohol is mainly attributed to the electron transfer from the reduced support to gold. This is in agreement with the results reported by Milone et al..$^{14,15}$ in studying the hydrogenation of benzalacetone and cinnamaldehyde over iron oxides supported gold catalysts.

\section{Conclusion}

Our data showed that the selectivity of gold catalysts is little dependent on the gold particle size, but is strongly affected by the nature of the support in the liquid phase selective hydrogenation of cinnamaldehyde. Unsupported and inert $\mathrm{SiO}_{2}$ supported AuNPs as well as AuNPs/TiO $/$ dried selectively hydrogenated the $\mathrm{C}=\mathrm{C}$ bond. Whereas $\mathrm{AuNPs} / \mathrm{TiO}_{2} / \mathrm{re}-$ duced and $\mathrm{Au} / \mathrm{TiO}_{2}-\mathrm{DP}$ exhibited good selectivity toward $\mathrm{C}=\mathrm{O}$ hydrogenation. Characterization results indicated an electron transfer from the reduced $\mathrm{TiO}_{2}$ support to gold, which may be the major factor for the enhanced selectivity toward cinnamyl alcohol.

\section{ACKNOWLEDGEMENTS}

The authors gratefully acknowledged the financial support provided by the National Natural Science Foundation of China (No. 21106134 and 21276230) and Zhejiang Provincial Natural Science Foundation of China (No. Y4100671 and Y4090304).

\section{REFERENCES}

P. Gallezot and D. Richard, Catal. Rev. Sci. Eng., 40, 81 (1998).

P. Claus, Top. Catal., 5, 51 (1998).

P. Maki-Arvela, J. Hajek, T. Salmi and D.Y. Murzin, Appl. Catal. A, 292, 1 (2005).
4. J.E. Bailie, H.A. Abdullah, J.A. Anderson, C.H. Rochester, N.V. Richardson, N. Hodge, J. G. Zhang, A. Burrows, C.J. Kiely and G.J. Hutchings, Phys. Chem. Chem. Phys., 3, 4113 (2001).

5. S. Schimpf, M. Lucas, C. Mohr, U. Rodemerck, A. Brückner, J. Radnik, H. Hofmeister and P. Claus, Catal. Today, 72, 63 (2002).

6. C. Mohr, H. Hofmeister and P. Claus, J. Catal., 213, 86 (2003).

7. C. Mohr, H. Hofmeister, J. Radnik and P. Claus, J. Am. Chem. Soc., 125, 1905 (2003)

8. J. Lenz, B.C. Campo, M. Alvarez and M.A. Volpe, J. Catal., 267, 50 (2009).

9. K.J. You, C.T. Chang, B.J. Liaw, C.T. Huang and Y.Z. Chen, Appl. Catal. A, 361, 65 (2009).

10. H.Y. Chen, C.T. Chang, S.J. Chiang, B.J. Liaw and Y.Z. Chen, Appl. Catal. A, 381, 209 (2010).

11. J.E. Bailie and G.J. Hutchings, Chem. Commun., 2151 (1999).

12. N. Abudukelimu, H.J. Xi, S.J. Qing, Y.B. Ma, Z.X. Gao and W.J. Eli, Asian J. Chem., 24, 5341 (2012).

13. C. Milone, R. Ingoglia, A. Pistone, G. Neri, F. Frusteri and S. Galvagno, J. Catal., 222, 348 (2004).

14. C. Milone, R. Ingoglia, L. Schipilliti, C. Crisafulli, G. Neri and S. Galvagno, J. Catal., 236, 80 (2005).

15. C. Milone, C. Crisafulli, R. Ingoglia, L. Schipilliti and S. Galvagno, Catal. Today, 122, 341 (2007)

16. B.C. Campo, S. Ivanova, C. Gigola, C. Petit and M.A. Volpe, Catal. Today, 133-135, 661 (2008).

17. P. Claus, Appl. Catal. A: Gen., 291, 222 (2005).

18. E. Bus, R. Prins and J.A. van Bokhoven, Catal. Commun., 8, 1397 (2007).

19. C. Milone, M.C. Trapani and S. Galvagno, Appl. Catal. A, 337, 163 (2008).

20. B. Campo, G. Santori, C. Petit and M. Volpe, Appl. Catal. A, 359, 79 (2009).

21. Q.Y. Yang, Y. Zhu, L. Tian, S.H. Xie, Y. Pei, H. Li, H.X. Li, M.H. Qiao and K.N. Fan, Appl. Catal. A: Gen., 369, 67 (2009).

22. M.M. Wang, L. He, Y.M. Liu, Y. Cao, H.Y. He and K.N. Fan, Green. Chem., 13, 602 (2011).

23. Y.X. Liu, L.F. Meng, Z.J. Wei and H.T. Shi, Chin. J. Catal., 32, 1269 (2011).

24. Y. Zhu, L. Tian, Z. Jiang, Y. Pei, S.H. Xie, M.H. Qiao and K.N. Fan, J. Catal., 281, 106 (2011).

25. L.N. Protasova, E.V. Rebrov, H.E. Skelton, A.E.H. Wheatley and J.C. Schouten, Appl. Catal. A, 399, 12 (2011).

26. E. Castillejos, E. Gallegos-Suarez, B. Bachiller-Baeza, R. Bacsa, P. Serp, A. Guerrero-Ruiz and I. Rodriguez-Ramos, Catal. Commun., 22, 79 (2012).

27. M.S. Ide, B. Hao, M. Neurock and R.J. Davis, ACS Catal., 2, 671 (2012).

28. M. Brust, D. Walker, D. Bethell, D.J. Schiffrin and R. Whyman, J. Chem. Soc., Chem. Commun., 801 (1994).

29. Y.X. Liu, T.F. Xing, Z.J. Wei, X.N. Li and W. Yan, Catal. Commun., 10, 2023 (2009).

30. H. Shi, N. Xu, D. Zhao and B.Q. Xu, Catal. Commun., 9, 1949 (2008).

31. K.M. Parida, N. Sahu, P. Mohapatra and M.S. Scurrell, J. Mol. Catal. A: Chem., 319, 92 (2010).

32. M.A.R. Dewan, G.Q. Zhang and O. Ostrovski, Metall. Mater. Trans. $B, 40,62$ (2009).

33. E.D. Park and J.S. Lee, J. Catal., 186, 1 (1999). 